\title{
A New Simple Plastic Chemotaxis Device of the Boyden Chamber Type Utilizing an Immunoassay Plate
}

\author{
Kazuyoshi WATANABE, Hideo NAKAGAWA* and Susumu TSURUFUJI \\ Department of Biochemistry. Faculty of Pharmaceutical Sciences. \\ Tohoku University. Aoba. Aramaki. Sendai 980. Japan
}

Accepted June 11.1985

\begin{abstract}
A new simple and economical plastic Boyden chamber for in vitro assay of leukocytes chemotaxis was devised by the use of a commercially available immunoassay plate. Zymosan-activated rat serum, formly-methionyl-leucylphenylalanine and leukotriene $\mathrm{B}_{4}$ caused concentration-dependent migration of the leukocytes into the lower chamber. About $50 \%$ of the cells loaded in the upper chamber migrated into the lower chamber for $80 \mathrm{~min}$ at the optimal concentrations of the three chemoattractants tested.
\end{abstract}

Leukocyte chemotaxis is an important aspect of host defense mechanisms. The assay method originally described by Boyden (1) for the measurement of leukocyte chemotaxis in vitro had been extensively used in accordance with the original method or with various modifications (2-6). Although the Boyden techniques made powerful contributions to the studies performed in this laboratory on leukocyte chemotaxis (6-10). we felt that it was still an urgent matter to improve the Boyden chamber to make it more economical and reliable as well as more easy to use. The present paper will describe a simplified, highly sensitive and reproducible modification of the Boyden technique for the measurement of leukocyte chemotaxis using a new disposable device made of plastic.

A commercially available immunoassay plate purchased from Eflab Oy Co. Finland (Titertec, Microtitration equipment, Flat bottom type with 12 holes that were each $7 \mathrm{~mm}$ in diameter and $11 \mathrm{~mm}$ in depth) was used for the lower chambers of the chemotaxis device. Another plate of the same type. of which the bottom of the holes had been

\footnotetext{
* Present adress: Department of Biochemistry. Faculty of Pharmaceutical Sciences, Toyama Medical and Pharmaceutical University. Sugitani 2630. Toyama 930-01. Japan
}

filed off by us, was placed upon the above described lower chambers to assemble the chemotaxis device (Fig. 1). Between each upper chamber and lower chamber, a polycarbonate filter (11-13 $\mathrm{mm}$ in diameter. Nuclepore Corp., Pleasanton, CA, U.S.A.) with pores of $2 \mathrm{~km}$ in diameter was tightly sandwiched with the aid of silicon grease (Toray Silicon. Tokyo, Japan) and rubber bands. Prior to placing the filter on the lower chamber, a test solution $(4.2 \mathrm{ml})$ of chemoattractant samples dissolved in RPMI-1640 medium (Nissui Seiyaku Co., Tokyo, Japan) was applied into the lower chamber, being careful to avoid air bubbles.

In order to collect leukocytes, male rats weighing 350-500 g (Sprague-Dawley strain, specific pathogen free, Charles River Japan (nc.. Kanagawa, Japan) were injected intraperitoneally with $\mathrm{Ca}^{2+}$-free Krebs-Ringer bicarbonate solution $(120 \mathrm{ml} / \mathrm{kg}$ body weight) containing $1 \%$ casein (Casein nach

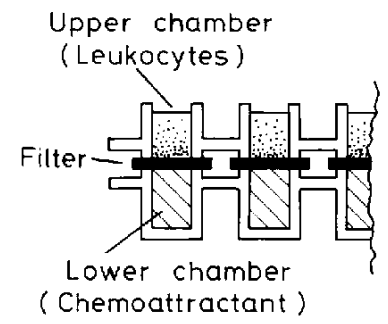

Fig. 1. Newly devised Boyden chamber. 
Hammarsten, Merck). Fourteen hours later, rats were killed by cutting the carotid arteries, and peritoneal fluids were collected and centrifuged at $400 \times \mathrm{g}$ for $5 \mathrm{~min}$ at $4^{\circ} \mathrm{C}$. and the cell pellet was washed twice with Gey's balanced salt solution. Cells were finally suspended in the RPMI-1640 medium at a concentration of $1 \times 10^{7}$ cells $/ \mathrm{ml}$.

Zymosan-activated serum to be used as a reference cytotaxin was prepared by incubating normal rat serum with $10 \mathrm{mg} / \mathrm{ml}$ zymosan (Zymosan A. Sigma Chemical Co. St. Louis, MO. U.S.A.) at $37^{\circ} \mathrm{C}$ for $30 \mathrm{~min}$ then removing zymosan particles under centrifugation, and finally heating at $56^{\circ} \mathrm{C}$ for 30 min. Normal rat serum treated at $56^{\circ} \mathrm{C}$ for $30 \mathrm{~min}$ was designated as heat-inactivated serum, and used as a control serum with no chemotactic activity.

After the cell suspension $(0.3 \mathrm{ml})$ was placed in the upper chambers, the chemotaxis device was kept at $37^{\circ} \mathrm{C}$ in a $\mathrm{CO}_{2}$ incubator with $5 \% \mathrm{CO}_{2}$ and $100 \%$ humidity for a suitable period. Then the fluid in the upper chamber was decanted away and remaining fluid and cells in the upper chamber were completely washed away by blowing a jet of water through a pipette. The filter and entire fluid in the lower chamber were then transferred into a test tube and agitated to make a cell suspension. Cells adhering on the inner surface of the lower chamber were detached by blowing a stream of the medium through a capped pipette and pooled with the above cell suspension. The cell number was then counted in a hemocytometer. Migration rate was calculated as follows:

(Number of leukocytes collected from the lower chamber/Number of leukocytes applied in the upper chamber $) \times 100(\%)$.

The leukocyte suspension was applied in the upper chamber charged with $2.5 \%$ zymosan-activated serum in the lower chamber, and then the number of leukocytes migrated into the lower chamber was determined after the incubation for 40,80 and $120 \mathrm{~min}$. The data values obtained were $(1.08 \pm 0.13) \times 10^{6}, \quad(1.60 \pm 0.09) \times 10^{6}$ and $(1.66=0.06) \times 10^{6}$ cells for the respective times, i.e., the number of leukocytes migrated into the lower chamber increased with the passage of time up to $80 \mathrm{~min}$ and then

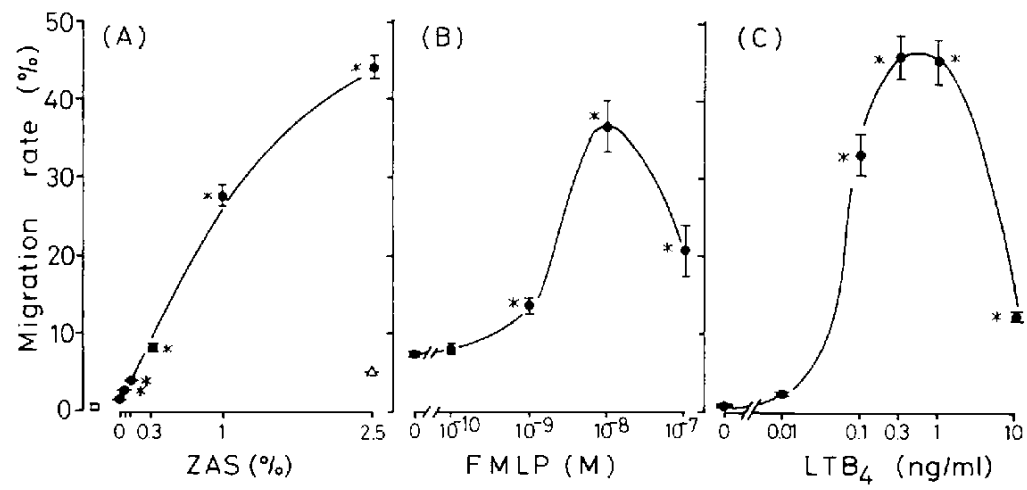

Fig. 2. Leukocyte chemotaxis in response to various chemoattractants. Boyden chambers were incubated for $80 \mathrm{~min}$ for the cel! migration. Each point represents the mean \pm S.E.M. of six determinations. Significant difference ( $P<0.01)$ from respective control is indicated by an asterisk. (A): Leukocyte chemotaxis in response to zymosan-activated serum. Zymosan-activated serum was applied to indicated concentrations in the lower chambers. Heat-inactivated normal rat serum was supplemented to adjust final serum concentration below the filter to $2.5 \%$. A group of the lower chambers contained medium only ( $\square$ ) and another group of the Boyden chambers contained $2.5 \%$ of zymosanactivated serum in both the upper and lower chambers $(\triangle)$. (B). Leukocyte chemotaxis in response to FMLP. FMLP dissolved in the medium containing $1 \%$ bovine serum albumin was applied in the lower chamber. (C) : Leukocyte chemotaxis in response to LTB LT L $_{4}$ (kindly supplied by Ono Pharmaceutical Co. Osaka, Japan) dissolved in the medium containing $0.2 \%$ bovine serum albumin was applied in the lower chamber. 
leveled off. When zymosan-activated serum was applied at various concentrations in the lower chamber, a dose-response relationship in the migration was observed as summarized in Fig. 2 (A). Background levels of the migration rate observed with $2.5 \%$ heatinactivated normal rat serum and the plain RPMI-1640 medium were $1.93 \pm 0.27$ and $0.80 \pm 0.10 \%$, respectively. The migration rate at $0.05 \%$ zymosan-activated serum was $2.77 \pm 0.07 \%$, i.e. significantly higher than the background levels. When $2.5 \%$ zymosanactivated serum was applied in both the upper and lower chambers, the migration rate was $4.9 \pm 0.9 \%$, while $2.5 \%$ zymosan-activated serum placed only in the lower chamber caused a migration rate of nearly $60 \%$. Therefore, this assay system was evidently capable of detecting the chemotactic activity for $0.05 \%$ zymosan-activated serum and distinguishing chemotactic migration of the cells from their random movement

In addition to zymosan-activated serum. this chemotaxis assay responds sensitively to some other chemotactic substances such as formly-methionyl-leucyl-phenylalanine (FMLP) and leukotriene $B_{4}\left(L^{2} B_{4}\right)$ as shown in Fig. 2 (B) and (C). Maximal chemotactic responses to $F M L P$ and $L T B_{4}$ were observed at $4.7 \mathrm{ng} / \mathrm{ml}\left(1 \times 10^{-8} \mathrm{M}\right)$ and $0.3 \mathrm{ng} / \mathrm{ml}$ $\left(0.9 \times 10^{-9} \mathrm{M}\right)$, respectively. These data are comparable to those reported by Palmer et al. (11).

Statistical variations of our experimental data were small, and sensitivity was enough to detect a very low level of chemoattractant such as $0.05 \%$ zymosan-activated serum. whereas the detection limit of Gallin's method employing ${ }^{51} \mathrm{Cr}$-labeled granulocytes was reported to be $0.5 \%$ zymosan-activated serum (5, 12, 13).

In conclusion, the present modification of the Boyden technique using a disposable plastic device provides a simple, sensitive and reliable assay method for our measurement of leukocyte chemotaxis.

\section{References}

1 Boyden, S: The chemotactic effect of mixtures of antibody and antigen on polymorphonuclear leukocytes. J. Exp. Med. 115, 453-466 (1962)
2 Ward, P.A., Cochrane, C.G. and Müller-Eberhard, H.J.: The role of serum component in chemotaxis of leukocytes in vitro. J. Exp. Med. 122, 327-346 (1965)

3 Ward, P.A.: Chemotaxis of polymorphonuclear leukocytes. Biochem. Pharmacol. Supp. 110, 99-105 (1968)

4 Baum, J., Mowat, A.G. and Kirk, J.A.: A simplified method for the measurement of chemotaxis of polymorphonuclear leukocytes from human blood. J. Lab. Clin. Med. 77, 501$509(1971)$

5 Gallin, J.I., Clark, R.A. and Kimball, H.R.: Granulocyte chemotaxis: An improved in vitro assay employing ${ }^{51} \mathrm{Cr}$-labeled granulocytes. J. immunol. 110, 233-240 (1973)

6 Kurihara, A., Ojima, F. and Tsurufuji, S.: Analysis of the effect of an anti-inflammatory steroid, dexamethasone, on neutrophil chemotaxis in the Boyden chamber with a modified ${ }^{51} \mathrm{Cr}$-labeling method. J. Pharmacobiodyn. 7, 747-754 (1984)

7 Kurihara, A., Ohuchi, K. and Tsurufuji, S.: Correlation of leukocyte accumulation with chemotactic activity in the exudate of an allergic air-pouch inflammation. Int. Arch. Allergy Appl. Immunol. 71, 368-370 (1983)

8 Kurihara, A, Ojima, F. and Tsurufuji, S.: Chemotactic factor production by rat polymorphonuclear leukocytes: Stimulation with opsonized zymosan particles and inhibition by dexamethasone. Biochem. Biophys. Res. Commun. 119, 720-725 (1984)

9 Tsurufuji, S., Kurihara, A., Kiso, S., Suzuki, Y. and Ohuchi, K.: Dexamethasone inhibits generation in inflammatory sites of the chemotactic activity attributable to leukotriene $B_{4}$. Biochem. Biophys. Res. Commun. 119, 884-890 (1984)

10 Kurihara, A., Ohuchi, K. and Tsurufuji, S.: Reduction by dexamethasone of chemotactio activity in inflammatory exudates. Eur. J. Pharmacol. 101, 11-16 (1984)

11 Palmer, R.M.J., Stepney, R.J., Higgs, G.A. and Eakins, K.E.: Chemokinetic activity of arachidonic acid lipoxygenase products on leukocytes of different aspects. Prostaglandins 20, 411-418 (1980)

12 Wilkinson, P.C.: Chemotaxis and Inflammation. Churchill Livingstone, Edinburgh and London (1974)

13 Wilkinson, P.C. and Allen, R.B.: Assay systems for measuring leukocyte locomotion: an overview. In Leukocyte Chemotaxis, Edited by Galin, J.I. and Quie, P.G., p. 1-24, Raven press, New York (1978) 